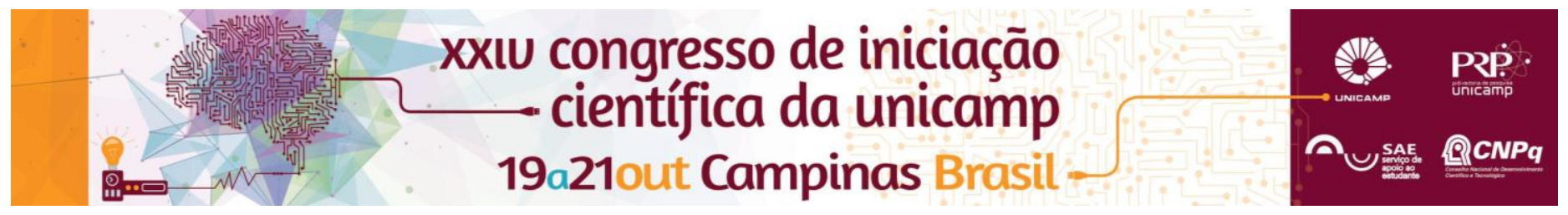

\title{
DESENVOLVIMENTO DE UM CONTROLADOR NEURAL APLICADO EM SISTEMAS QUÍMICOS MULTIVARIÁVEIS.
}

\author{
Lucas C. de Souza*, Flávio V. da Silva
}

\section{Resumo}

O desenvolvimento de controladores avançados representa uma promissora área de aplicação industrial e acadêmica. A importância estratégica desta área de conhecimento se dá na manutenção da qualidade final dos produtos obtidos e na redução do consumo de energia. Este trabalho propõe o desenvolvimento teórico e experimental de um controlador neural aplicado em sistemas multivariáveis. Neste estudo serão selecionadas as arquiteturas adequadas ao desenvolvimento do controlador neural e estas serão testadas no sistema de fermentação de etanol (Nagy, 2007) por simulação e posteriormente na planta didática de tanques acoplados (multivariável) experimentalmente. O desempenho do controlador neural desenvolvido para cada sistema será determinado por meio da análise dos índices baseados na integral do erro (ITAE) sob diferentes perturbações. Neste trabalho espera-se a obtenção de subsídios experimentais para a análise do controlador neural aplicado em processos complexos não lineares.

\section{Palavras-chave}

controle neural, automação, controle de processos

\section{Introdução}

Há décadas, as indústrias têm dado grande enfoque à automação de sistemas e o seu desenvolvimento, tendo em vista as melhorias que tal tecnologia proporciona. Dentre elas pode-se destacar a produção de bens e serviço com menor custo, menor tempo de execução, maior quantidade e maior qualidade. No entanto, não é isso que se observa hoje nas fábricas, sendo empregada em sua grande maioria, a teoria clássica de controle. Dessa forma, torna-se necessário um maior esforço acadêmico para a aplicação teórica e experimental em diferentes processos com métodos de controle avançado.

Este trabalho propõe o desenvolvimento de um controlador neural aplicado em sistemas multivariáveis. Neste estudo serão selecionadas as arquiteturas adequadas ao desenvolvimento do controlador neural e estas serão testadas no sistema de fermentação de etanol (Nagy, 2007) por simulação e comparadas com os resultados obtidos com o controlador clássico

\section{Resultados e Discussão}

O modelo de Nagy foi desenvolvido no toolbox Simulink, do programa Matlab. Aplicou-se a teoria clássica de controle para sintonizar um controlador PID, o qual serviu como base de comparação.Com objetivo de treinar a rede neural, foi realizado um controle manual da planta com auxílio do Indusoft, um software supervisório, em comunicação online com o Matlab através de um servidor OPC.

A resposta de ambos os controladores frente a duas perturbações encontram-se na Figura 1, enquanto que o comportamento das variáveis manipuladas, na Figura 2. Em ambas, o PID é representado em vermelho e o controlador neural em azul.

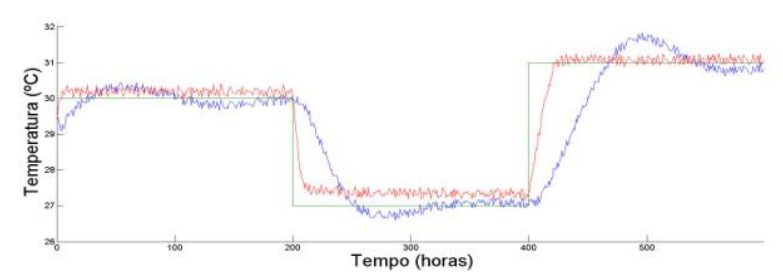

Figura 1. Resposta dos controladores neural (azul) e PID (vermelho) frente a duas perturbações servo

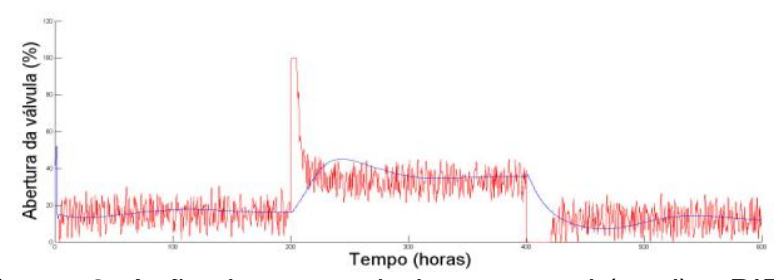

Figura 2. Ação dos controladores neural (azul) e PID (vermelho) frente a duas perturbações servo

\section{Conclusões}

A rede neural que apresentou o melhor desempenho e generalização no controle do sistema foi configurada com cinco neurônios escondidos e treinada com três tempos anteriores. Embora o seu desempenho tenha sido pior que 0 de um PID pelo critério ITAE, observa-se que o controlador neural foi capaz de eliminar o offset para todas as oscilações além de atuar de maneira mais suave, comprovando a sua eficácia para processos não lineares.

\section{Agradecimentos}

Agradecimentos ao PIBIC/CNPq pelo auxílio financeiro. Ao professor Flávio Vasconselos da Silva pela oportunidade e apoio na elaboração deste trabalho.

\footnotetext{
Braga, A. de P., Ludemir, T. B., Carvalho A. C. P. de L. F., Redes Neurais Artificiais teoria e aplicações. Rio de Janeiro: LTC - Livros Técnicos e Científicos Editora S.A., 2000.

Nagy, Z. K. Model based control of a yeast fermentation bioreactor using optimally designed artificial neural networks. Chemical Engineering Journal 127 95-109, 2007.
} 